\title{
A Matéria autossuficiente: Garantindo o acesso aberto e amplo à comunidade científica
}

${ }^{1}$ Gerente Financeiro - revista Matéria

${ }^{2}$ Editor-Chefe - revista Matéria

Universidade Federal do Rio de Janeiro - UFRJ, Laboratório de Hidrogênio - LabH2-COPPE, Av. Moniz Aragão, 207, 21941-594, Rio de Janeiro, RJ, Brasil.

e-mail: revmateria.echefe@gmail.com

Recentemente, a revista Matéria contribuiu para agilizar a disponibilização de artigos aceitos para publicação ao criar a Pré-Publicação [1]. Nesse momento, toma uma atitude que garantirá a sustentabilidade financeira da revista e, adicionalmente, contribuirá para agilizar e ganhar mais qualidade nos processos de editoração e publicação.

A revista Matéria sempre atuou em regime de acesso aberto aos leitores e continuará a fazê-lo. Nosso corpo editorial não só objetiva o amplo acesso ao conteúdo científico, como o garante e o disponibiliza a todo público mantendo esse valor como um pilar fundamental na história do periódico.

Essa característica, o acesso aberto, gera, porém, custos internos significativos. Isso contrasta com a grande dificuldade da obtenção contínua de financiamento às atividades da revista, já que o apoio por parte de órgãos governamentais é periódico e eventual. O esforço para cobrir os gastos financeiros da revista tem aumentado muito nos últimos anos, quando o apoio financeiro decresceu e os custos de processamento aumentaram. Além dos custos, a proporção atual do fluxo de publicação da Matéria recebemos cerca de 1000 manuscritos para avaliação por ano, dos quais pouco mais de um quarto é publicado - canalizou nossa equipe em busca de maior eficiência. Portanto, optamos pela transferência total do processo de editoração da revista Matéria ao SciELO. Dessa maneira, nosso corpo editorial passará a focar exclusivamente nos processos científicos de seleção de manuscritos e revisão por pares, visando aumentar ainda mais a qualidade das publicações.

O mês de julho de 2021 marca a mudança dos processos de editoração e o início da cobrança de custo de processamento por artigo (CPA) aos autores de manuscritos aceitos para publicação na revista, e que tenham sido submetidos a partir de então. Com intuito de continuar sem finalidade lucrativa, o periódico é agora suportado pela Associação Brasileira do Hidrogênio - ABH2 - e foi então fixada uma tabela de CPAs (figurando abaixo) que arca minimamente com os custos fixos de publicação/editoração e com valores abaixo daqueles comumente praticados pelo mercado em geral.

\begin{tabular}{|l|l|}
\hline Caso & Custo \\
\hline Autores Brasileiros & R\$ 650,00 \\
\hline Autores Latino-Americanos & US\$ 130,00 \\
\hline Demais Autores & US\$230,00 \\
\hline
\end{tabular}

Com a cobrança do CPA, a revista Matéria não mais dependerá de fluxo de caixa com verba oriunda de apoio governamental, pois a publicação, assim como seus custos inerentes, estará atrelada ao pagamento do CPA por parte dos autores. Dessa forma, o tempo estimado entre a submissão de um manuscrito e a sua disponibilização online cairá drasticamente. Ademais, vale ressaltar o que foi brevemente supracitado, que é o fato de o Corpo Editorial passar a trabalhar voltado exclusivamente ao conteúdo científico, abolindo a necessidade de horas despendidas com o processo editorial, que passará a 
ser responsabilidade do SciELO, impactando positivamente na qualidade do processo de revisão por pares que continua sendo de total responsabilidade do nosso Corpo Editorial.

Vale ainda mencionar, que as mudanças nos procedimentos ora citados foram extensivamente discutidas entre o Editor-Chefe, Editores Associados e Editores Assistentes, a equipe de Apoio Editorial da revista além do pessoal responsável pelos processos editoriais do SciELO, garantindo a contribuição de todos nesse novo momento da revista. Por fim, garantimos que os autores que já tenham submetido seus manuscritos antes de 01 de julho de 2021 estejam isentos da cobrança de CPA, mantendo assim uma transição com menos impactos e com transparência.

\section{BIBLIOGRAFIA}

[1] MIRANDA, P. E. V. de "Pré-Publicação de artigos na revista Matéria", Matéria (Rio de Janeiro), v. 25, n. 3, e-12838, 2020.

\section{ORCID}

Bernardo Jordão M. Sarruf | https://orcid.org/0000-0002-4842-545X

Paulo Emílio V. de Miranda | https://orcid.org/0000-0002-8968-3308 